\title{
Corrigendum: Landscape of monoallelic DNA accessibility in mouse embryonic stem cells and neural progenitor cells
}

Jin Xu, Ava C Carter, Anne-Valerie Gendrel, Mikael Attia, Joshua Loftus, William J Greenleaf, Robert Tibshirani, Edith Heard \& Howard Y Chang

Nat. Genet.; doi:10.1038/ng.3769; corrected online 13 February 2017

In the version of this article initially published online, there were two errors. In the section "Three classes of monoallelic elements" in the main text, "We classified all monoallelically accessible elements (1,966 elements)" should have read "1,964 elements." In the legend for Figure 5c, the number of elements open in ESCs should have been given as 234 instead of 35. The errors have been corrected in the print, PDF and HTML versions of this article.

\section{Corrigendum: Acquired CYP19A1 amplification is an early specific mechanism of aromatase inhibitor resistance in ER $\alpha$ metastatic breast cancer}

\author{
Luca Magnani, Gianmaria Frigè, Raffaella Maria Gadaleta, Giacomo Corleone, Sonia Fabris, Mannus H Kempe, Pernette J Vershure, \\ Iros Barozzi, Valentina Vircillo, Sung-Pil Hong, Ylenia Perone, Massimo Saini, Andreas Trumpp, Giuseppe Viale, Antonino Neri, \\ Simak Ali, Marco Angelo Colleoni, Giancarlo Pruneri \& Saverio Minucci \\ Nat. Genet.; doi:10.1038/ng.3773; corrected online 31 January 2017
}

In the version of this article initially published online, the names of authors Hermannus Kempe and Pernette J. Verschure were spelled incorrectly. These errors have been corrected in the print, PDF and HTML versions of this article.

\section{Corrigendum: A study of allelic diversity underlying flowering-time adaptation in maize landraces}

\begin{abstract}
J Alberto Romero Navarro, Martha Wilcox, Juan Burgueño, Cinta Romay, Kelly Swarts, Samuel Trachsel, Ernesto Preciado, Arturo Terron, Humberto Vallejo Delgado, Victor Vidal, Alejandro Ortega, Armando Espinoza Banda, Noel Orlando Gómez Montiel, Ivan Ortiz-Monasterio, Félix San Vicente, Armando Guadarrama Espinoza, Gary Atlin, Peter Wenzl, Sarah Hearne \& Edward S Buckler Nat. Genet.; doi:10.1038/ng.3784; corrected online 20 February 2017
\end{abstract}

In the version of this article initially published online, the name of author Martha Willcox was misspelled as Martha Wilcox. The error has been corrected in the print, PDF and HTML versions of this article.

\section{Erratum: Uncovering Listeria monocytogenes hypervirulence by harnessing its biodiversity}

Mylène M Maury, Yu-Huan Tsai, Caroline Charlier, Marie Touchon, Viviane Chenal-Francisque, Alexandre Leclercq, Alexis Criscuolo, Charlotte Gaultier, Sophie Roussel, Anne Brisabois, Olivier Disson, Eduardo P C Rocha, Sylvain Brisse \& Marc Lecuit

Nat. Genet. 48, 308-313 (2016); published online 1 February 2016; corrected after print 6 March 2017

In the version of this article initially published, the titles of the $x$ axes in Figure $5 \mathrm{~b}$ and $5 \mathrm{c}$ should have been "Brain/blood CFU ratio" instead of "Blood/brain CFU ratio," and the title of the $z$ axis in Figure 2c should have been "\% of isolates" instead of "Number of isolates." The errors have been corrected in the HTML and PDF versions of the article. 